\title{
Long-term changes in renal function and perfusion in heart failure patients with reduced ejection fraction
}

\author{
Nicolas F. Schroten ${ }^{1} \cdot$ Kevin Damman ${ }^{1}$ Mattia A. E. Valente ${ }^{1} \cdot$ Tom D. Smilde $^{2}$. \\ Dirk J. van Veldhuisen ${ }^{1} \cdot$ Gerjan Navis $^{3}$ - Carlo A. Gaillard ${ }^{3} \cdot$ Adriaan A. Voors $^{1}$. \\ Hans L. Hillege ${ }^{1,4}$
}

Received: 3 March 2015 / Accepted: 9 June 2015/Published online: 30 June 2015

(c) The Author(s) 2015. This article is published with open access at Springerlink.com

\begin{abstract}
Introduction Little is known about the natural course of renal function and renal hemodynamics in heart failure patients with reduced ejection fraction (HFREF).

Methods and results We prospectively studied effective renal plasma flow (ERPF) and glomerular filtration rate (GFR) in 73 HFREF patients with ${ }^{125}$ I-iothalamate $/{ }^{131} \mathrm{I}$ hippuran clearances with a mean follow-up of $34.6 \pm 4.4$ months. Fifteen percent were female, with age $58 \pm 12$ years and left ventricular ejection fraction (LVEF) $29 \pm 10 \%$. Baseline GFR was $81 \pm 23 \mathrm{~mL} / \mathrm{min} /$ $1.73 \mathrm{~m}^{2}$ and declined $0.6 \pm 4.7 \mathrm{~mL} / \mathrm{min} / 1.73 \mathrm{~m}^{2}$ per year. Baseline ERPF was $292 \pm 83 \mathrm{~mL} / \mathrm{min} / 1.73 \mathrm{~m}^{2}$ and declined $4.3 \pm 19 \mathrm{~mL} / \mathrm{min} / 1.73 \mathrm{~m}^{2}$ per year. Of the baseline variables, older age and high urinary kidney injury molecule-1 were the only variables associated with GFR decline $(p<0.05)$. Following stepwise backward analysis,
\end{abstract}

Electronic supplementary material The online version of this article (doi:10.1007/s00392-015-0881-9) contains supplementary material, which is available to authorized users.

Nicolas F. Schroten

nicolasschroten@gmail.com

Hans L. Hillege

J.L.Hillege@umcg.nl

1 Department of Cardiology, University Medical Center Groningen, Groningen, The Netherlands

2 Department of Cardiology, Scheper Ziekenhuis, Emmen, The Netherlands

3 Department of Internal Medicine, University Medical Center Groningen, Groningen, The Netherlands

4 Department of Epidemiology, University Medical Center Groningen, Hanzeplein 1, 9713GZ Groningen, The Netherlands only age $(p<0.001)$ remained significant. In addition, we found an association between change in GFR and changes in ERPF, $N$-terminal pro-brain natriuretic peptide and renovascular resistance. In the multivariable analysis, only the change in ERPF remained significantly associated with a change in GFR $(p<0.001)$.

Conclusion In this cohort of stable chronic HFREF patients, the average decline in GFR over time was small. The decline of GFR was associated with a higher age and a lower baseline GFR, and was strongly related to changes in renal perfusion.

Keywords Cardiorenal $\cdot$ Heart failure $\cdot$ Renal blood flow $\cdot$ Kidney $\cdot$ Biomarkers

\section{Introduction}

Both chronic kidney disease (CKD) and worsening renal function are common in heart failure patients [1-3] and among the most powerful predictors of morbidity and mortality in this population [4]. However, little is known about the natural course of renal function in heart failure patients and determinants of long-term renal function decline. The cause of renal dysfunction in HFREF is thought to be multifactorial $[5,6]$. It has been attributed to medication [7], renin-angiotensin-aldosterone system (RAAS) activation [8], sympathetic nervous system (SNS) activation and inflammation. Decreased renal perfusion is likely the key determinant [9], via decreased renal perfusion pressure, an increase in renovascular resistance (RVR), increase in renal venous pressure or all of the above [10]. However, these associations have mostly been described in cross-sectional studies. The limited number of longitudinal studies has mostly focused on acute worsening 
of renal function, and few data are available on predictors of long-term estimated glomerular filtration rate (GFR) changes in heart failure patients with reduced ejection fraction (HFREF) [11-14]. All these studies used changes in serum creatinine to estimate GFR, which is considered a surrogate for the functioning kidney tissue. However, creatinine-based renal function estimates are not always accurate in estimating kidney function decline [15] and provide no information on renal hemodynamics.

Using gold standard techniques for measuring renal function, we studied the change in renal function over time and its clinical, biochemical and hemodynamic predictors in patients with heart failure. We previously described the cross-sectional associations. Renal blood flow showed the strongest association with GFR. In turn, $N$-terminal probrain natriuretic peptide (NT-proBNP), plasma renin activity, soluble vascular cell adhesion molecule-1 (sVCAM-1) levels and urinary albumin excretion (UAE) showed the strongest associations with renal blood flow [9]. In the current analysis, we investigated if these parameters are also associated with long-term renal function decline, measured using radioactive labeled specific renal function tracers.

\section{Methods}

\section{Patient population}

Details on the study design and patient population have been published previously [9]. In brief, 120 clinically stable HFREF patients, with left ventricular ejection fraction (LVEF) $<45 \%$ and stable heart failure medication for at least 1 month underwent renal function measurements using ${ }^{125}$ I-iothalamate and ${ }^{131}$ I-hippuran clearance techniques at the University Medical Center Groningen, The Netherlands. Blood and urine samples were collected, a physical examination performed and the patient's history documented. Patients were contacted after 3 years and all investigations were repeated. The study was approved by the ethics committee of the study center, and all subjects gave written informed consent. The study was conducted in accordance with Declaration of Helsinki guidelines.

\section{Renal and cardiac function measurements}

Renal function measurements were performed using radioactive labeled tracers, ${ }^{125} \mathrm{I}$-iothalamate and ${ }^{131} \mathrm{I}$-hippuran, as described previously [16]. This method has an intra- and inter-test variation of 1.9 and $2.9 \%$, respectively, for GFR. The intra-subject day-to-day $\mathrm{CV}$ of effective renal plasma flow (ERPF) is $5.0 \%$ [17]. The filtration fraction was calculated as GFR/ERPF. RVR was calculated as (mean arterial pressure/ERPF $) \times(1-$ hematocrit) and expressed in $\mathrm{mmHg} / \mathrm{mL} / \mathrm{min}$. GFR and ERPF were corrected for $1.73 \mathrm{~m}^{2}$ of body surface area, calculated using the Dubois formula. LVEF was determined by nuclear ventriculography.

\section{Laboratory methods}

Patients were all in the supine position during renal measurements, and a venous blood sample was drawn $2 \mathrm{~h}$ after the start of the measurements. Routine hematology, blood chemistry and urinalysis were performed within an hour of collection. Additional blood and urine samples were immediately centrifuged and stored at $-80{ }^{\circ} \mathrm{C}$. Urinary markers of renal damage were measured in $24 \mathrm{~h}$ urine collections and corrected for urinary creatinine as described previously [18]. A detailed description of the methods and analytical variation is provided in supplement 1 .

\section{Follow-up}

All patients were asked to return for a follow-up visit between 24 and 36 months after baseline renal function measurements. All measurements performed at baseline were repeated including laboratory analyses, renal function measurements using radioactive labeled tracers and nuclear ventriculography. Adverse events during follow-up were determined via interview and case record extraction. Adverse events included death from any cause, heart transplantation, cardiovascular event (myocardial infarction or primary percutaneous coronary intervention or primary coronary artery bypass grafting) and first hospitalization for worsening heart failure.

\section{Statistical analyses}

Continuous data are presented as mean \pm standard deviation (SD) when normally distributed, as median and interquartile range when non-normally distributed and as frequencies and percentages for categorical variables. Differences between groups were tested using Student's $T$ test, Kruskal-Wallis or Chi-square test as appropriate. Linear regression analysis was carried out to determine the association of baseline variables with change in GFR and to test the association of changes in hemodynamic parameters with changes in GFR. Linear regression models with delta variables were corrected for baseline values of the variables of interest. Age and sex were included in all multivariable models. Skewed variables were log-transformed where appropriate. Variables associated with the univariable model at $p<0.1$ were included in a stepwise, backward multivariable regression analysis, with a threshold for 
variable retention of $p<0.1$. All reported probability values are two tailed, and a $p$ value of $<0.05$ was considered to be statistically significant. Statistical analyses were performed and graphics created using STATA version 11.0, College Station, TX, USA.

\section{Results}

Of the 120 patients included at baseline, 73 returned for follow-up measurements (Fig. 1). The baseline characteristics of the study population are presented in Table 1 . In brief, $15 \%$ were female, with a mean age of $58 \pm 12$ years. The left ventricular ejection fraction (LVEF) was $29 \pm 10 \%$. Most patients had New York Heart Association (NYHA) class II or III heart failure symptoms. All patients were on an angiotensin-converting enzyme inhibitor and/or angiotensin receptor blocker and most were on beta-blocker therapy or aldosterone receptor antagonists.

Baseline GFR was $81 \pm 23 \mathrm{~mL} / \mathrm{min} / 1.73 \mathrm{~m}^{2}$ and baseline ERPF was $292 \pm 83 \mathrm{~mL} / \mathrm{min} / 1.73 \mathrm{~m}^{2}$. The mean follow-up time was $34.6 \pm 4.4$ months. In patients with a complete follow-up, the mean decline in GFR was $0.6 \pm 4.7 \mathrm{ml} / \mathrm{min} / 1.73 \mathrm{~m}^{2}$ per year and ERPF declined $4.3 \pm 19 \mathrm{~mL} / \mathrm{min} / 1.73 \mathrm{~m}^{2}$ per year. There was no significant difference in the rate of renal function decline between patients with a GFR below and above $60 \mathrm{~mL} / \mathrm{min} / 1.73 \mathrm{~m}^{2}$ at baseline $(p=0.81)$. Patients who were lost to follow-up are also presented in Table 1. Patient who died or had a heart transplant during follow-up had a lower blood pressure, GFR, ERPF and filtration fraction, and a higher RVR, UAE and NT-proBNP and were more often using angiotensin receptor blockers (ARB) or aldosterone receptor antagonists (ARA) compared with patients who completed follow-up. There were no significant differences between patients who completed follow-up and those who were lost to follow-up for other reasons.

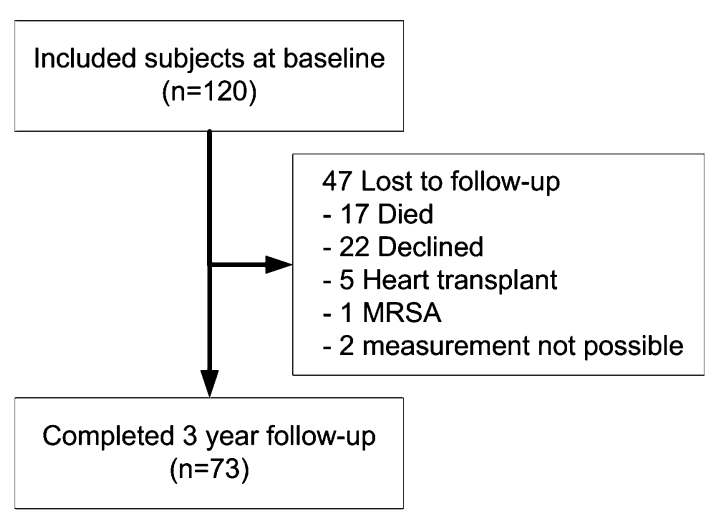

Fig. 1 Patient disposition

\section{Predictors of changes in GFR}

\section{Baseline variables}

Associations of baseline characteristics and laboratory tests with change in GFR are shown in Table 2. Baseline age, sex, mean arterial pressure, neutrophil gelatinase-associated lipocalin (NGAL) and kidney injury molecule 1 (KIM-1) showed a relation with change in GFR at $p<0.1$ (Table 2). Following stepwise backward analysis, only older age $(p<0.001)$ remained significantly associated with higher GFR decline in a multivariable model.

\section{Changes in hemodynamics and renal perfusion}

In general, patients who completed follow-up maintained a relatively stable hemodynamic profile. Changes in LVEF $(+3.3 \pm 11 \%)$ mean arterial pressure $(-0.13 \pm 10 \mathrm{mmHg}), \quad$ NT-proBNP $[-0.6 \quad(-265$ to $+250.6) \mathrm{ng} / \mathrm{L}]$ and RVR $(0.01 \pm 0.05 \mathrm{mmHg} / \mathrm{mL} / \mathrm{min})$ were modest. A decrease in ERPF and NT-proBNP and increase in RVR were associated with a decrease in GFR, while LVEF was not (Table 3; Fig. 2). In the multivariable analysis, only change in ERPF remained significantly associated with a change in GFR. In parallel to changes in GFR, an increase in RVR and a decrease in NT-proBNP and LVEF were associated with a decrease in ERPF. In multivariable analysis, only RVR and NT-proBNP remained significantly associated with changes in ERPF (results not shown). Change in mean arterial pressure was not associated with a change in either GFR or ERPF.

\section{Discussion}

In the present study of patients with stable HFREF, we found only a small decrease in GFR over a longer period of time, in the order of magnitude also reported as the agerelated decline in the general population. Likewise, ERPF decline did not differ much from the age-related decline rate in the general population [19]. Change in GFR was strongly associated with a parallel change in ERPF. Only higher age and lower baseline GFR predicted a greater decline in GFR over time, but none of the tested urinary biomarkers of renal damage or hemodynamic parameters were associated with GFR decline.

Several studies have focused on markers predicting worsening renal function in chronic heart failure, with limited success. The identified risk factors include congestion [20], vascular disease, diuretics, advanced age, left ventricular ejection fraction and worse renal function at baseline $[4,7,11]$. Furthermore, NGAL and NT-proBNP have been linked to worsening renal function in acute heart 
Table 1 Baseline characteristics
Table 2 Association of baseline markers with GFR change $\left(\mathrm{mL} / \mathrm{min} / 1.73 \mathrm{~m}^{2}\right)$ per year corrected for baseline GFR, age and sex

\begin{tabular}{|c|c|c|c|}
\hline Variable & $\begin{array}{l}\text { With follow-up } \\
(n=73)\end{array}$ & $\begin{array}{l}\text { Lost to follow-up } \\
(n=25)\end{array}$ & $\begin{array}{l}\text { Died/HTX } \\
(n=22)\end{array}$ \\
\hline Age (years) & $58 \pm 12$ & $58 \pm 12$ & $62 \pm 12$ \\
\hline Female sex, $n(\%)$ & $11(15 \%)$ & $7(28 \%)$ & $6(27 \%)$ \\
\hline RR systolic (mmHg) & $121 \pm 18$ & $127 \pm 21$ & $105 \pm 20^{\#}$ \\
\hline RR diastolic (mmHg) & $71 \pm 11$ & $70 \pm 11.2$ & $62 \pm 11^{\#}$ \\
\hline Heart rate $(\mathrm{bpm})$ & $64 \pm 12$ & $66 \pm 12$ & $68 \pm 16$ \\
\hline Ischemic etiology, $n(\%)$ & $39(53 \%)$ & $11(44 \%)$ & $10(46 \%)$ \\
\hline LVEF $(\%)$ & $29 \pm 10$ & $30 \pm 10$ & $28 \pm 10$ \\
\hline GFR $\left(\mathrm{mL} / \mathrm{min} / 1.73 \mathrm{~m}^{2}\right)$ & $81 \pm 23$ & $75 \pm 28$ & $50 \pm 26^{\#}$ \\
\hline ERPF $\left(\mathrm{mL} / \mathrm{min} / 1.73 \mathrm{~m}^{2}\right)$ & $292 \pm 83$ & $264 \pm 90$ & $202 \pm 73^{\#}$ \\
\hline Filtration fraction (\%) & $28 \pm 3$ & $28 \pm 6$ & $24 \pm 8^{\#}$ \\
\hline $\mathrm{RVR}(\mathrm{mmHg} / \mathrm{mL} / \mathrm{min}) *$ & $0.17(0.15-0.22)$ & $0.19(0.14-0.29)$ & $0.22(0.18-0.31)^{\#}$ \\
\hline $\mathrm{UAE}(\mathrm{mg} / 24 \mathrm{~h})^{*}$ & $8(6-12)$ & $12(7-35)$ & $18(7-49)^{\#}$ \\
\hline NT-proBNP $(\mathrm{ng} / \mathrm{mL})^{*}$ & $465(219-1100)$ & $635(286-1700)$ & $2200(950-5000)^{\#}$ \\
\hline Urine NGAL $(\mu \mathrm{g} / 24 \mathrm{~h})^{*}$ & $15(7-31)$ & $17(11-34)$ & $9(2-33)$ \\
\hline Urine KIM-1 (U/24 h)* & 408 (144-995) & $416(111-1800)$ & $279(20-1100)$ \\
\hline Urine NAG (ng/24 h)* & $4.4(2.2-6.6)$ & $3.7(2.5-7.9)$ & $3.4(2.4-7.5)$ \\
\hline ACE inhibitor, $n(\%)$ & $65(89 \%)$ & $21(84 \%)$ & $16(73 \%)$ \\
\hline $\mathrm{ARB}, n(\%)$ & $8(11 \%)$ & $3(12 \%)$ & $7(32 \%)^{* *}$ \\
\hline Beta-blocker, $n(\%)$ & $63(86 \%)$ & $20(80 \%)$ & $18(82 \%)$ \\
\hline Aldosterone antagonist, $n(\%)$ & $18(25 \%)$ & $6(24 \%)$ & $13(59 \%)^{\#}$ \\
\hline
\end{tabular}

Normally distributed data are presented as mean $\pm \mathrm{SD} ; *$ skewed data as median (p25-p75)

$R R$ blood pressure, $L V E F$ left ventricular ejection fraction, GFR glomerular filtration rate, ERPF effective renal plasma flow, $R V R$ renovascular resistance, $U A E$ urinary albumin excretion, $N T$-proBNP $N$-terminal pro-brain natriuretic peptide, $N G A L$ neutrophil gelatinase-associated lipocalin, $K I M-1$ kidney injury molecule 1, NAG $N$-acetyl-b-D-glucosaminidase, $A R B$ angiotensin receptor blocker, $A C E$ angiotensinconverting enzyme

** $p<0.05$ and ${ }^{\#} \mathrm{p}<0.01$ compared with patients with complete follow-up

\begin{tabular}{lclrc}
\hline Variable & Coef & $95 \%$ CI & Beta & $p$ value \\
\hline Age (years) & -0.25 & $(-0.34$ to -0.17$)$ & -0.64 & $<0.001$ \\
Female sex & 2.7 & $(-0.31$ to 5.75$)$ & 0.21 & 0.077 \\
MAP $(\mathrm{mmHg})$ & -0.08 & $(-0.17$ to 0.01$)$ & -0.22 & 0.064 \\
LVEF $(\%)$ & -0.08 & $(-0.21$ to 0.04$)$ & -0.17 & 0.20 \\
ERPF $\left(\mathrm{mL} / \mathrm{min} / 1.73 \mathrm{~m}^{2}\right)$ & 0.01 & $(-0.02$ to 0.04$)$ & 0.17 & 0.54 \\
RVR $(\mathrm{mmHg} / \mathrm{mL} / \mathrm{min})$ & -7.9 & $(-27$ to 9.9$)$ & -0.15 & 0.38 \\
Filtration fraction $(\%)$ & -0.09 & $(-0.42$ to 0.24$)$ & -0.06 & 0.61 \\
NT-proBNP $(\mathrm{ng} / \mathrm{mL}) *$ & -0.29 & $(-0.98$ to 0.40$)$ & -0.11 & 0.41 \\
Hemoglobin $(\mathrm{mmol} / \mathrm{l})$ & 0.15 & $(-1.6$ to 1.9$)$ & -0.02 & 0.87 \\
CRP $(\mathrm{mg} / \mathrm{L}) *$ & -0.17 & $(-0.93$ to 0.60$)$ & -0.05 & 0.67 \\
24 h Urine sodium $(\mathrm{mmol})$ & -4.6 & $(-14$ to 4.8$)$ & -0.44 & 0.29 \\
UAE $(\mathrm{mg} / 24 \mathrm{~h})^{*}$ & -0.19 & $(-0.79$ to 0.41$)$ & -0.08 & 0.53 \\
NGAL $(\mu \mathrm{g} / 24 \mathrm{~h})^{*}$ & -0.60 & $(-1.3$ to 0.11$)$ & -0.21 & 0.096 \\
KIM-1 $(\mathrm{U} / 24 \mathrm{~h})^{*}$ & -0.55 & $(-1.0$ to -0.7$)$ & -0.27 & 0.027 \\
NAG $(\mathrm{ng} / 24 \mathrm{~h})^{*}$ & -0.34 & $(-1.1$ to 0.41$)$ & -0.11 & 0.36 \\
\hline
\end{tabular}

GFR glomerular filtration rate, MAP mean arterial pressure, $L V E F$ left ventricular ejection fraction, $E R P F$ effective renal plasma flow, $R V R$ renovascular resistance, $N T$-proBNP $N$-terminal pro-brain natriuretic peptide, $C R P$ C-reactive protein, $U A E$ urinary albumin excretion, $N G A L$ neutrophil gelatinase-associated lipocalin, KIM-1 kidney injury molecule $1, N A G N$-acetyl-b-D-glucosaminidase

* log-transformed variables 
Table 3 Associations between hemodynamic changes and changes in GFR

\begin{tabular}{lllrr}
\hline & Coef & $95 \%$ CI & Beta & $p$ value \\
\hline Delta MAP (mmHg) & -0.17 & $(-0.47$ to 0.13$)$ & -0.14 & 0.25 \\
Delta LVEF $(\%)$ & 0.20 & $(-0.08$ to 0.47$)$ & 0.16 & 0.16 \\
Delta ERPF $\left(\mathrm{mL} / \mathrm{min} / 1.73 \mathrm{~m}^{2}\right)$ & 0.15 & $(0.11$ to 0.19$)$ & 0.62 & $<0.001$ \\
Delta RVR $(\mathrm{mmHg} / \mathrm{mL} / \mathrm{min})$ & -110 & $(-172$ to -47.9$)$ & -0.43 & 0.001 \\
Delta $\log -\mathrm{NT}-\mathrm{proBNP}(\mathrm{ng} / \mathrm{mL})$ & 3.20 & $(1.17$ to 5.22$)$ & 0.34 & 0.002 \\
\hline
\end{tabular}

Models include age, sex and baseline values of the variable of interest

GFR glomerular filtration rate, MAP mean arterial pressure, $L V E F$ left ventricular ejection fraction, ERPF effective renal plasma flow, $R V R$ renovascular resistance, $N T$-proBNP $N$-terminal pro-brain natriuretic peptide

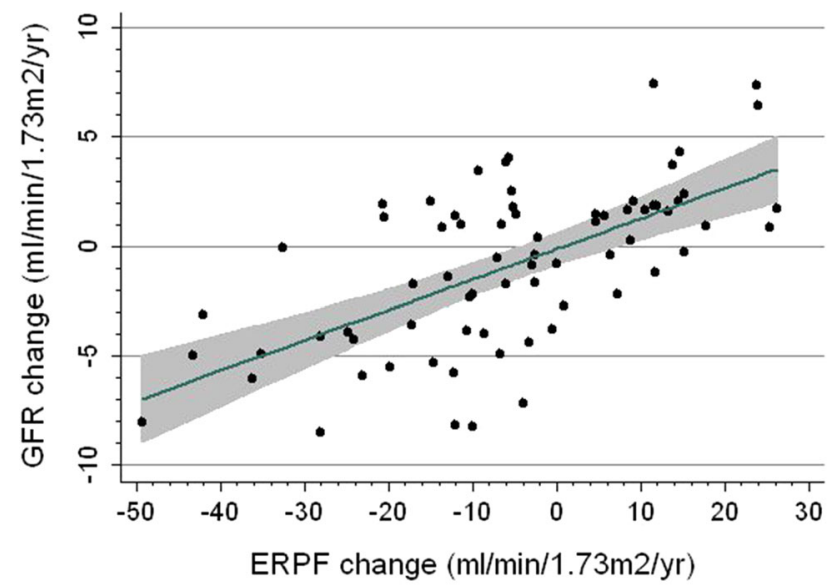

Fig. 2 Changes in GFR and ERPF

failure [21-23] and chronic heart failure [24]. However, all these studies used plasma creatinine to estimate GFR and cannot differentiate between changes in hemodynamics and kidney damage. In a previous analysis we demonstrated a strong relation of renal blood flow with GFR in HFREF patients [9].

In the current analysis, we found that none of the urinary biomarkers or hemodynamic parameters at baseline could predict renal function decline. Our study may have limited power, because of the small change in GFR over time; however, most of the aforementioned studies also demonstrated a limited estimated GFR decline over time and by using radioactive labeled tracers we can measure small changes in GFR more accurately. We cannot exclude that deceased subjects had a more rapid renal function decline. These subjects did have a lower GFR and ERPF and higher NT-proBNP at baseline; however, tubular damage markers were not elevated in these subjects. What is most remarkable is that they had a high RVR in combination with a low filtration fraction and low blood pressure. This may reflect the kidneys' inability to maintain glomerular perfusion pressure. They were more often on double reninangiotensin-aldosterone system (RAAS) blockers, which may decrease the filtration fraction by vasodilation of the efferent glomerular arteriole; however, this should cause a decrease in RVR. The high RVR, therefore, must reflect a different mechanism, possibly compromised kidney perfusion by increased venous pressure, sympathetic nerve activation or a decreased amount of functioning glomeruli.

In our study, we found that the change in ERPF was the strongest determinant of the change in GFR. In contrast, in healthy individuals, GFR remains relatively stable with moderate changes in renal blood flow [25]. It may be speculated that impaired systemic circulation causes decreased ERPF and, because of impaired intra-renal regulatory mechanisms, a parallel decline in GFR, but it may also imply that both ERPF and GFR are affected by intrarenal hemodynamic changes. Both congestion and reduced cardiac output are thought to influence renal function in heart failure patients. In our study, an increase in NT-proBNP was associated with an increase in ERPF and GFR. This is counterintuitive, since higher NTproBNP is associated with worsening cardiac function [26]. However, changes in volume status also influence NTproBNP levels, suggesting that not only congestion, but also hypovolemia causes renal function decline in these patients. Another explanation for the observed relationship is that kidney damage affects both ERPF and GFR. However, many patients showed an increase in ERPF and an associated increase in GFR, which suggests changes in hemodynamics rather than in viable kidney tissue.

This study has several limitations. First, not all patients were able to participate in the second measurement. The deceased patients had worse baseline renal function, lower blood pressure and higher NT-proBNP. Second, we only had two measurements; therefore, we cannot establish if there is a linear trend over time and cannot account for fluctuations. Furthermore, our study has a modest sample size. The measurements performed, however, are the gold standard for measuring renal function, with a day-to-day variation coefficient of less than $3 \%$ for GFR and $5 \%$ for ERPF. Patients were mostly stable on medication; however, some patients had minor changes in dose or type of 
medication. Finally, this was a relatively young cohort, with mostly male Caucasian patients.

\section{Conclusion}

In these stable chronic HFREF patients, long-term changes in GFR were small, but strongly related to changes in ERPF. None of the investigated urinary biomarkers and hemodynamic parameters other than baseline GFR and age could predict changes in GFR. This underlines the need for the development of new renal risk markers and demonstrates that changes in GFR are mostly driven by changes in renal hemodynamics in chronic HFREF patients. Intervention trials should investigate whether targeting ERPF may improve GFR and reduce cardiac events and mortality.

Acknowledgments This work was supported by the Netherlands Heart Foundation (Grant 2006B157 to dr. K. Damman). We would like to thank Dr. M. K. Szymanski and Dr. W. T. Ruifrok for their help in conducting the study.

\section{Compliance with ethical standards}

Conflict of interest CA.J.M.G. received consultancy fees and/or research grants from Novartis, Amgen, Roche, Baxter and Vifor. A.A.V received consultancy fees and/or research grants from Alere, AstraZeneca, Bayer, Boehringer Ingelheim, Cardio3Biosciences, Celladon, Johnson and Johnson, Merck/MSD, Novartis, Servier, Torrent, Trevena and Vifor. The other authors report no conflicts of interest.

Open Access This article is distributed under the terms of the Creative Commons Attribution 4.0 International License (http://creativecommons.org/licenses/by/4.0/), which permits unrestricted use, distribution, and reproduction in any medium, provided you give appropriate credit to the original author(s) and the source, provide a link to the Creative Commons license, and indicate if changes were made.

\section{References}

1. Cruz DN, Gheorghiade M, Palazzuoli A, Ronco C, Bagshaw SM (2011) Epidemiology and outcome of the cardio-renal syndrome. Heart Fail Rev 16:531-542

2. Ohlmeier C, Mikolajczyk R, Frick J, Prutz F, Haverkamp W, Garbe E (2015) Incidence, prevalence and 1-year all-cause mortality of heart failure in Germany: a study based on electronic healthcare data of more than six million persons. Clin Res Cardiol

3. Franke J, Zugck C, Wolter JS, Frankenstein L, Hochadel M, Ehlermann P, Winkler R, Nelles M, Zahn R, Katus HA, Senges J (2012) A decade of developments in chronic heart failure treatment: a comparison of therapy and outcome in a secondary and tertiary hospital setting. Clin Res Cardiol 101:1-10

4. Damman K, Valente MA, Voors AA, O'Connor CM, van Veldhuisen DJ, Hillege HL (2014) Renal impairment, worsening renal function, and outcome in patients with heart failure: an updated meta-analysis. Eur Heart J 35:455-469

5. Bongartz LG, Cramer MJ, Doevendans PA, Joles JA, Braam B (2005) The severe cardiorenal syndrome: 'Guyton revisited'. Eur Heart J 26:11-17
6. Damman K, Kalra PR, Hillege H (2010) Pathophysiological mechanisms contributing to renal dysfunction in chronic heart failure. J Ren Care 36(Suppl 1):18-26

7. Knight EL, Glynn RJ, McIntyre KM, Mogun H, Avorn J (1999) Predictors of decreased renal function in patients with heart failure during angiotensin-converting enzyme inhibitor therapy: results from the studies of left ventricular dysfunction (SOLVD). Am Heart J 138:849-855

8. Schroten NF, Gaillard CA, van Veldhuisen DJ, Szymanski MK, Hillege HL, de Boer RA (2012) New roles for renin and prorenin in heart failure and cardiorenal crosstalk. Heart Fail Rev 17:191-201

9. Smilde TD, Damman K, van der Harst P, Navis G, Westenbrink BD, Voors AA, Boomsma F, van Veldhuisen DJ, Hillege HL (2009) Differential associations between renal function and "modifiable" risk factors in patients with chronic heart failure. Clin Res Cardiol 98:121-129

10. Damman K, Navis G, Smilde TD, Voors AA, van der Bij W, van Veldhuisen DJ, Hillege HL (2007) Decreased cardiac output, venous congestion and the association with renal impairment in patients with cardiac dysfunction. Eur J Heart Fail 9:872-878

11. de Silva R, Nikitin NP, Witte KK, Rigby AS, Goode K, Bhandari S, Clark AL, Cleland JG (2006) Incidence of renal dysfunction over 6 months in patients with chronic heart failure due to left ventricular systolic dysfunction: contributing factors and relationship to prognosis. Eur Heart J 27:569-581

12. MacDowall P, Kalra PA, O'Donoghue DJ, Waldek S, Mamtora H, Brown K (1998) Risk of morbidity from renovascular disease in elderly patients with congestive cardiac failure. Lancet 352:13-16

13. Forman DE, Butler J, Wang Y, Abraham WT, O'Connor CM, Gottlieb SS, Loh E, Massie BM, Rich MW, Stevenson LW, Young JB, Krumholz HM (2004) Incidence, predictors at admission, and impact of worsening renal function among patients hospitalized with heart failure. J Am Coll Cardiol 43:61-67

14. Krumholz HM, Chen YT, Vaccarino V, Wang Y, Radford MJ, Bradford WD, Horwitz RI (2000) Correlates and impact on outcomes of worsening renal function in patients $>$ or $=65$ years of age with heart failure. Am J Cardiol 85:1110-1113

15. Tent H, Waanders F, Krikken JA, Heerspink HJ, Stevens LA, Laverman GD, Navis G (2012) Performance of MDRD study and CKD-EPI equations for long-term follow-up of nondiabetic patients with chronic kidney disease. Nephrol Dial Transplant 27(Suppl 3):iii89-95

16. Donker AJ, van der Hem GK, Sluiter WJ, Beekhuis H (1977) A radioisotope method for simultaneous determination of the glomerular filtration rate and the effective renal plasma flow. Neth J Med 20:97-103

17. Apperloo AJ, de Zeeuw D, Donker AJ, de Jong PE (1996) Precision of glomerular filtration rate determinations for long-term slope calculations is improved by simultaneous infusion of $125 \mathrm{I}-$ iothalamate and 131I-hippuran. J Am Soc Nephrol 7:567-572

18. Damman K, Van Veldhuisen DJ, Navis G, Vaidya VS, Smilde TD, Westenbrink BD, Bonventre JV, Voors AA, Hillege HL (2010) Tubular damage in chronic systolic heart failure is associated with reduced survival independent of glomerular filtration rate. Heart 96:1297-1302

19. Weinstein JR, Anderson S (2010) The aging kidney: physiological changes. Adv Chronic Kidney Dis 17:302-307

20. Damman K, van Veldhuisen DJ, Navis G, Voors AA, Hillege HL (2008) Urinary neutrophil gelatinase associated lipocalin (NGAL), a marker of tubular damage, is increased in patients with chronic heart failure. Eur J Heart Fail 10:997-1000

21. Pfister R, Muller-Ehmsen J, Hagemeister J, Hellmich M, Erdmann E, Schneider CA (2011) NT-pro-BNP predicts worsening 
renal function in patients with chronic systolic heart failure. Intern Med J 41:467-472

22. Aghel A, Shrestha K, Mullens W, Borowski A, Tang WH (2010) Serum neutrophil gelatinase-associated lipocalin (NGAL) in predicting worsening renal function in acute decompensated heart failure. J Card Fail 16:49-54

23. Macdonald S, Arendts G, Nagree Y, Xu XF (2012) Neutrophil Gelatinase-Associated Lipocalin (NGAL) predicts renal injury in acute decompensated cardiac failure: a prospective observational study. BMC Cardiovasc Disord 12:8-2261-12-8

24. Damman K, Masson S, Hillege HL, Voors AA, van Veldhuisen DJ, Rossignol P, Proietti G, Barbuzzi S, Nicolosi GL, Tavazzi L,
Maggioni AP, Latini R (2013) Tubular damage and worsening renal function in chronic heart failure. JACC Heart Fail $1: 417-424$

25. Palmer BF (2002) Renal dysfunction complicating the treatment of hypertension. N Engl J Med 347:1256-1261

26. Leistner DM, Klotsche J, Pieper L, Palm S, Stalla GK, Lehnert H, Silber S, Marz W, Wittchen HU, Zeiher AM (2013) Prognostic value of NT-pro-BNP and hs-CRP for risk stratification in primary care: results from the population-based DETECT study. Clin Res Cardiol 102:259-268 